\title{
Efeito alcalinizante de soluções eletrolíticas intravenosas com concentrações elevadas de lactato de sódio infundidas em bezerros sadios
}

\author{
[Alkalinizing effect of intravenous electrolyte solutions with high sodium lactate \\ concentrations infused in healthy calves] \\ J.R.C. Junqueira ${ }^{1}$, M.R.S. Balarin ${ }^{2}$, K.K.M.C. Flaiban ${ }^{2}$, D.S. Barbosa ${ }^{2}$, J.A.N. Lisboa ${ }^{2 *}$ \\ ${ }^{1}$ Universidade do Oeste Paulista - Presidente Prudente, SP \\ ${ }^{2}$ Universidade Estadual de Londrina - Londrina, PR
}

\begin{abstract}
RESUMO
Com o objetivo de investigar o potencial alcalinizante de soluções eletrolíticas com concentrações elevadas de lactato de sódio em bezerros sadios, foram idealizadas seis soluções contendo 28,56 e 84mEq/L de lactato (L28, L56 e L84) ou de bicarbonato (B28, B56 e B84), com concentrações de sódio, de potássio e de cálcio semelhantes às da solução de Ringer com lactato (SRL). As soluções contendo bicarbonato de sódio foram utilizadas como padrão para comparação. Seis bezerros receberam, por via intravenosa, todas as seis soluções, uma a cada vez, com intervalo de quatro a cinco dias entre as infusões, em volume correspondente a $10 \%$ do peso corporal, durante cinco horas $(20 \mathrm{~mL} / \mathrm{kg} / \mathrm{h})$. Amostras de sangue venoso e de urina foram coletadas antes de iniciar a infusão, na metade do volume, ao término e duas horas e meia após o término da infusão. Determinaram-se concentração de proteína plasmática total, $\mathrm{pH}$ sanguíneo e urinário, $\mathrm{pCO}_{2}, \mathrm{HCO}_{3}{ }^{-}, \mathrm{BE}$, concentração plasmática e urinária de lactato $\mathrm{L} \mathrm{e}$ concentrações séricas e urinárias de $\mathrm{Na}^{+}, \mathrm{K}^{+}, \mathrm{Cl}^{-}$e creatinina. A solução L28, idêntica à SRL, provocou discreto incremento da reserva alcalina e, consequentemente, produziu efeito alcalinizante insuficiente para a correção de estados de acidose metabólica. A solução L84, além de provar-se segura, provocou o maior aumento da reserva alcalina, equivalente à $\mathrm{B} 84$, e, assim, produziu efeito capaz de corrigir o grau moderado de acidose metabólica.
\end{abstract}

Palavras-chave: bezerro, equilíbrio ácido-base, terapia com fluidos, acidose metabólica

\begin{abstract}
The alkalinizing effects of electrolyte solutions with high concentration of sodium lactate were evaluated in healthy calves. Six solutions were formulated containing 28, 56 and 84mEq/L of lactate (L28, L56 and L84) or bicarbonate (B28, B56 and B84), and sodium, potassium and calcium concentrations similar to the lactated Ringer's solution (LRS). The solutions containing sodium bicarbonate were used as a standard for comparison. Six calves received all six solutions intravenously, one at a time, with an interval of four to five days between the infusions, in a volume corresponding to $10 \%$ of body weight, during five hours $(20 \mathrm{~mL} / \mathrm{kg} / \mathrm{h})$. Venous blood and urine samples were taken prior to the beginning of the infusion, at a half volume, at the end and two and a half hours after the end of the infusion. Total plasma protein concentration, urinary and blood $\mathrm{pH}$, blood $\mathrm{pCO}_{2}, \mathrm{HCO}_{3}{ }^{-}$and $\mathrm{BE}$, plasma and urine L lactate concentration and serum and urine $\mathrm{Na}^{+}, \mathrm{K}^{+}, \mathrm{Cl}$ and creatinine concentrations were measured. The L28 solution, equal to LRS, caused a slight increase in the alkaline reserve, producing an alkalinizing effect insufficient for correction of metabolic acidosis states. The L84 solution was safe and produced the greater increase in the alkaline reserve, equivalent to B84 solution, and suitable for correcting a moderate degree of metabolic acidosis.
\end{abstract}

Keywords: calf, acid-base balance, fluid therapy, metabolic acidosis

Recebido em 12 de abril de 2013

Aceito em 19 de fevereiro de 2014

*Autor para correspondência (corresponding author)

E-mail: janlisboa@uel.br 


\section{INTRODUÇÃO}

Estados de acidose metabólica devem ser tratados com soluções tamponantes, e as soluções de bicarbonato de sódio infundidas por via intravenosa são consideradas de eleição para o tratamento dessa condição (Constable, 2003). No entanto, a administração rápida ou o uso excessivo desse tampão podem ocasionar alcalose iatrogênica, hipernatremia, hipopotassemia, acidose paradoxal do líquido cefalorraquidiano e hemorragia intracraniana (Hartsfield et al., 1981). O cálculo da quantidade necessária de bicarbonato a ser administrada depende do resultado do exame hemogasométrico, o que não está disponível para o clínico veterinário, na maioria das vezes.

Como alternativa, as bases metabolizáveis, como lactato, acetato, gluconato, citrato e propionato, podem exercer efeito alcalinizante. $\mathrm{O}$ gluconato e o citrato, entretanto, mostraram-se agentes alcalinizantes ineficazes quando administrados por via intravenosa em bezerros saudáveis, enquanto o propionato, o acetato e o lactato produziram ação alcalinizante similar à do bicarbonato nesses animais (Naylor e Forsyth, 1986; Kasari, 1999).

O Ringer com lactato (SRL) é uma solução cristaloide poli-iônica balanceada, empregada para a correção simultânea da desidratação, dos desequilíbrios eletrolíticos e da acidose metabólica, tratando-se da única opção comercial brasileira para administração intravenosa que contém tampão metabolizável em sua composição. Em razão de possuir concentração baixa de lactato $(28 \mathrm{mEq} / \mathrm{L}), \quad$ o potencial alcalinizante é comprovadamente reduzido tanto em bezerros sadios (Lisbôa et al., 2007) quanto em ovelhas sadias (Flaiban et al., 2009).

Soluções contendo concentração elevada de lactato $\mathrm{L}(150 \mathrm{mEq} / \mathrm{L})$ provaram-se eficazes para aumentar a reserva alcalina em bezerros (Naylor e Forsyth, 1986) e em garrotes (Leal et al., 2007) sadios, demonstrando efeito equivalente ao da solução de bicarbonato na mesma concentração.
A combinação com outros eletrólitos não foi testada anteriormente nesse tipo de solução para administração intravenosa.

Acredita-se que soluções eletrolíticas com concentrações maiores de lactato possam corrigir a acidose mais rápida e efetivamente do que a SRL, o que possibilita sua aplicação comercial futura a custo relativamente reduzido. $\mathrm{O}$ objetivo deste estudo foi investigar o potencial alcalinizante e avaliar os possíveis efeitos colaterais de soluções eletrolíticas com concentrações elevadas de lactato de sódio, administradas por via intravenosa em bezerros sadios.

\section{MATERIAL E MÉTODOS}

O projeto foi aprovado pelo Comitê de Ética em Experimentação Animal da Universidade Estadual de Londrina, sob protocolo CEEA/UEL 26/06. Foram desenvolvidas as soluções cristaloides poli-iônicas com as composições descritas na Tab. 1, tomando-se como base a solução comercial de Ringer com lactato (L28) e respeitando-se a sua osmolaridade (ligeiramente hiposmolar) e as concentrações de sódio, de potássio e de cálcio. A concentração de lactato foi duplicada (L56) ou triplicada (L84). As soluções de bicarbonato equimolares às de lactato (B28, B56 e B84) foram empregadas como padrão para comparação. As soluções foram preparadas pouco antes do início da infusão, empregando-se recipientes estéreis e cuidados de assepsia para evitar, ao máximo, qualquer grau de contaminação. Foram utilizados água bidestilada esterilizada comercial em frasco de $1.000 \mathrm{~mL}$ (água para injetáveis; Indústria Farmacêutica Texon), cloreto de sódio $(\mathrm{NaCl})$, cloreto de potássio $(\mathrm{KCl})$, cloreto de cálcio $\left(\mathrm{CaCl}_{2}\right)$ e lactato de sódio ou bicarbonato de sódio $\left(\mathrm{NaHCO}_{3}\right)$, todos os ingredientes puros para análise $\left(\right.$ Synth $^{\circledR} ; \quad$ Labsynth). As concentrações de lactato $\mathrm{L}$ foram mensuradas e corresponderam a $98 \%$ do lactato total presente na solução. 
Efeito alcalinizante...

Tabela 1. Composição iônica $(\mathrm{mEq} / \mathrm{L})$ e osmolaridade calculada $(\mathrm{mOsm} / \mathrm{L})$ das soluções utilizadas para administração intravenosa em bezerros sadios

\begin{tabular}{lcccccc}
\hline Constituinte & L 28 $^{\mathrm{a}}$ & L56 & L84 & B28 & B56 & B84 \\
\hline Sódio & 130 & 130 & 130 & 130 & 130 & 130 \\
\hline Cloreto & 109 & 81 & 53 & 109 & 81 & 53 \\
Potássio & 4 & 4 & 4 & 4 & 4 & 4 \\
Cálcio & 3 & 3 & 3 & - & - & - \\
Lactato & 28 & 56 & 84 & - & - & - \\
Bicarbonato & - & - & - & 28 & 56 & 84 \\
Osmolaridade & 275 & 275 & 275 & 272 & 272 & 272 \\
\hline
\end{tabular}

${ }^{a}$ Composição idêntica à da solução comercial de Ringer com lactato.

${ }^{b}$ Depósito de pedido de patente ao Instituto Nacional da Propriedade Industrial (INPI), número PI0804912-2, em 13/11/2008.

Foram utilizados seis bezerros mestiços clinicamente sadios (três machos e três fêmeas), pertencentes ao rebanho do Hospital Veterinário da UEL, com idade de $17 \pm 2$ dias no início e $47 \pm 4$ dias ao término do experimento, e peso inicial de $46,1 \pm 6,6 \mathrm{~kg}(\mathrm{Md}=46,0 \mathrm{~kg})$ e final de $53,1 \pm 10,2 \mathrm{~kg} \quad(\mathrm{Md}=53,5 \mathrm{~kg})$. Os bezerros permaneceram em contato com as mães e mamaram natural e espontaneamente.

As soluções estudadas foram infundidas por via intravenosa, em cada um dos bezerros, a uma velocidade de $20 \mathrm{~mL} / \mathrm{kg} / \mathrm{h}$ (1 litro/hora) totalizando $5 \mathrm{~L}$ ( $10 \%$ do peso corporal) por bezerro em cinco horas de administração contínua. A veia auricular foi mantida cateterizada (BD Angiocath ${ }^{\circledR}$ 20G; Becton Dickinson Indústrias Cirúrgicas Ltda.) para essa finalidade. As infusões foram realizadas no período da manhã, com os bezerros privados de alimento desde a noite da véspera, a fim de se evitar a interferência da alimentação sobre o equilíbrio ácido-base (Lisbôa et al., 2003). Cada bezerro recebeu todas as seis soluções propostas, uma a cada vez, com intervalo de quatro a cinco dias entre as infusões. A ordem de infusão das soluções foi sorteada em cada bezerro.

Os bezerros permaneceram sob observação constante durante todo o período de duração das infusões, com a finalidade de se detectarem possíveis manifestações que caracterizassem efeitos colaterais. Exames físicos foram realizados a cada hora, no início, durante e ao término da administração das soluções, aferindose a temperatura corporal e as frequências cardíaca e respiratória.

Amostras de sangue venoso e de urina foram coletadas em quatro momentos: antes do início da infusão, na metade da infusão (duas horas e meia), ao término da infusão (cinco horas) e duas horas e meia após o término da infusão (sete horas e meia). As amostras de sangue foram coletadas por punção da veia jugular em frascos a vácuo contendo anticoagulante EDTA e fluoreto de sódio, para as determinações de proteína plasmática total (PPT) e do lactato $\mathrm{L}$, respectivamente, e em frascos sem anticoagulante para as determinações dos eletrólitos e da creatinina. O plasma foi obtido por centrifugação da amostra em, no máximo, 10 minutos após a coleta, e o soro sanguíneo foi obtido por centrifugação após a retração do coágulo. Plasma e soro foram conservados por congelação $\left(20^{\circ} \mathrm{C}\right.$ negativos) até o momento das análises. Amostras de sangue venoso foram coletadas para a hemogasometria, empregandose seringas plásticas de $3 \mathrm{~mL}$ contendo cerca de $0,08 \mathrm{~mL}$ (400UI) de heparina sódica (Liquemine $^{\circledR}$; Roche Química e Farmacêutica S/A) como anticoagulante, mantidas em condições anaeróbicas e conservadas em banho de água gelada por até, no máximo, quatro horas após a coleta, conforme as recomendações de Lisbôa et al. (2001). As amostras de urina foram obtidas por micção espontânea ou induzidas por massagem prepucial nos machos ou perineal nas fêmeas.

As determinações do $\mathrm{pH}$ e da densidade da urina foram realizadas logo após a coleta. As demais determinações foram executadas posteriormente nas amostras conservadas por congelação. As determinações sanguíneas de $\mathrm{pH}$, pressão parcial de dióxido de carbono $\left(\mathrm{pCO}_{2}\right)$, concentração de bicarbonato $\left(\mathrm{HCO}_{3}{ }^{-}\right)$e excesso de bases (BE) foram realizadas em medidor automático de $\mathrm{pH}$ e de gases sanguíneos (Medica EasyStat; EUA). A concentração das PPT e a densidade urinária 
foram mensuradas por refratometria. As concentrações de lactato $\mathrm{L}$ foram determinadas no plasma, na urina e nas soluções infundidas, empregando-se o método enzimático (lactato; Bioclin Química Básica Ltda.) com leitura espectrofotométrica (Bio 2000; Bioplus Produtos para Laboratórios). As concentrações séricas e urinárias de sódio $\left(\mathrm{Na}^{+}\right)$, de potássio $\left(\mathrm{K}^{+}\right)$e de cloretos $\left(\mathrm{Cl}^{-}\right)$foram determinadas por meio do método de eletrodo íon seletivo (Dimension Clinical Chemistry System, Dade Behring, Siemens; Alemanha), e as de creatinina por meio do método cinético (creatinina; Bioclin Química Básica Ltda.) com leitura espectrofotométrica. O $\mathrm{pH}$ urinário foi mensurado com potenciômetro eletrônico ( $\mathrm{pH}$ meter Tec-2; Tecnal Equipamentos para Laboratórios).

Foram calculadas as seguintes variáveis, empregando-se as fórmulas correspondentes:

- hiato aniônico - anion gap (AG) (DiBartola, 2006): $\mathrm{AG}=\left(\mathrm{Na}^{+}+\mathrm{K}^{+}\right)-\left(\mathrm{Cl}^{-}+\mathrm{HCO}_{3}^{-}\right)$;

- diferença de íons fortes-Strong Ion Difference (SID) (Constable et al., 2005):

$\mathrm{SID}=\left(\mathrm{Na}^{+}+\mathrm{K}^{+}\right)-\left(\mathrm{Cl}^{-}\right)$;

- concentração total de ácidos fracos não voláteis $\left(\mathrm{A}_{\text {tot }}\right)$ (Constable et al., 2005):

$\mathrm{A}_{\mathrm{tot}}=\mathrm{PPT}(\mathrm{g} / \mathrm{dL}) \times 4,1$

- excreção fracionada de eletrólitos e de lactato (Garry et al., 1990):

$\mathrm{EF}(\mathrm{a})=\frac{\text { Concentração urinária de (a) } \mathrm{x} \text { creatinina plasmática } \times 100}{\text { Concentração plasmática de }(\mathrm{a}) \mathrm{x} \text { creatinina urinária }}$ sendo (a) a substância excretada.

Adotou-se delineamento experimental em blocos (cada bezerro um bloco) e parcelas subdivididas (seis tratamentos como parcelas e quatro momentos como subparcelas). A análise de variância unifatorial de medidas repetidas foi empregada para testar o efeito de cada solução separadamente. Para a comparação entre as soluções em cada momento estudado, foi realizada a análise de variância unifatorial. Quando a estatística $\mathrm{F}$ resultou significativa, o teste de Tukey foi empregado para contraste entre as médias, admitindo-se probabilidade de erro de 5\% (Curi, 1998). O programa SigmaStat para Windows, versão 3.1, foi utilizado para a análise estatística.

\section{RESULTADOS E DISCUSSÃO}

A solução de Ringer com lactato (SRL) serviu como base para a formulação das demais soluções estudadas, duplicando-se (L56) ou triplicando-se (L84) a concentração do lactato de sódio. A administração da SRL (L28) em volume correspondente a $10 \%$ do peso corporal produziu interferência de pequena magnitude no equilíbrio ácido-base dos bezerros e não interferiu no equilíbrio eletrolítico. As elevações de $\mathrm{pH}$, $\mathrm{HCO}_{3}{ }^{-}$e $\mathrm{BE}$ ao término da infusão foram discretas (Fig. 1). Resultado semelhante foi obtido por Lisbôa et al. (2007) e por Flaiban et al. (2009) em bezerros e ovelhas sadios, respectivamente, e isso contraria o conceito de que a SRL possa ser eficaz para a correção da acidose em animais enfermos. Em bezerros acidóticos, a SRL administrada em volume correspondente a $8 \%$ do peso corporal também não foi capaz de promover a correção do desequilíbrio (Nakagawa et al., 2009).

A ausência de interferência da SRL com os eletrólitos plasmáticos pode ser atribuída à composição dessa solução, a qual possui concentrações de $\mathrm{Na}^{+}, \mathrm{K}^{+}$e $\mathrm{Cl}^{-}$relativamente parecidas com as do plasma. Pelo mesmo motivo, essa solução possui diferença de íons fortes (SID efetiva reduzida), estimada em $28 \mathrm{mEq} / \mathrm{L}$, o que corresponde à sua concentração de lactato, que, sendo metabolizado, não permanece no plasma como íon forte (Constable, 2003).

O lactato é o precursor de bases presente na solução e deve ser metabolizado para que ocorra o efeito alcalinizante. A metabolização ocorre principalmente no fígado, por meio das vias gliconeogênica $\left(2 \mathrm{CH}_{3} \mathrm{CH}(\mathrm{OH}) \mathrm{COO}^{-} \leftrightarrow\right.$ $\left.2 \mathrm{CH}_{3} \mathrm{COCOOH}+2 \mathrm{H}^{+}+6 \mathrm{H}_{2} \mathrm{O} \leftrightarrow \mathrm{C}_{6} \mathrm{H}_{12} \mathrm{O}_{6}\right)$ e oxidativa $\left(2 \mathrm{CH}_{3} \mathrm{CH}(\mathrm{OH}) \mathrm{COO}^{-}+2 \mathrm{H}^{+}+6 \mathrm{O}_{2} \rightarrow\right.$ $\left.6 \mathrm{CO}_{2}+6 \mathrm{H}_{2} \mathrm{O}\right)$, nas quais existe remoção de íons hidrogênio $\left(\mathrm{H}^{+}\right)$do meio aquoso (Kasari, 1999), ou pela transformação direta em íon bicarbonato $\left(\mathrm{CH}_{3} \mathrm{CH}(\mathrm{OH}) \mathrm{COO}^{-}+3 \mathrm{O}_{2} \Rightarrow 2 \mathrm{CO}_{2}+2 \mathrm{H}_{2} \mathrm{O}+\right.$ $\mathrm{HCO}_{3}{ }^{-}$) (Constable, 2003). O potencial de alcalinização da SRL é reduzido porque a concentração do lactato é baixa.

$\mathrm{O}$ efeito alcalinizante foi incrementado com o aumento da concentração de lactato nas soluções (Fig. 1). Comparadas à L28, as soluções L56 e 
L84 provocaram elevações mais acentuadas do $\mathrm{pH}$, do $\mathrm{HCO}_{3}^{-}$e do $\mathrm{BE}(\mathrm{P}<0,001)$, e isso foi proporcional à concentração do lactato presente. A infusão da L84 chegou a provocar alcalose iatrogênica ao término da administração. $\mathrm{O}$ pH e o $\mathrm{BE}$ iniciais de 7,393 $\pm 0,016$ e $-0,50 \pm 1,69 \mathrm{mmol} / \mathrm{L}$ se elevaram para $7,475 \pm 0,014$ e $9,35 \pm 1,54 \mathrm{mmol} / \mathrm{L}$ no final da infusão $(\mathrm{P}<0,001)$. Nesses bezerros a $\mathrm{pCO}_{2}$ se elevou de $40,13 \pm 2,34 \mathrm{mmHg}$ para $46,23 \pm 3,16 \mathrm{mmHg}(\mathrm{P}<0,001)$ como mecanismo de resposta compensatória.

A hipótese que sustentou a formulação das soluções desenvolvidas e testadas no presente trabalho foi a de que o efeito alcalinizante seria aumentado ao se elevar a concentração do lactato de sódio na solução. Há duas explicações possíveis para isso. A primeira leva em

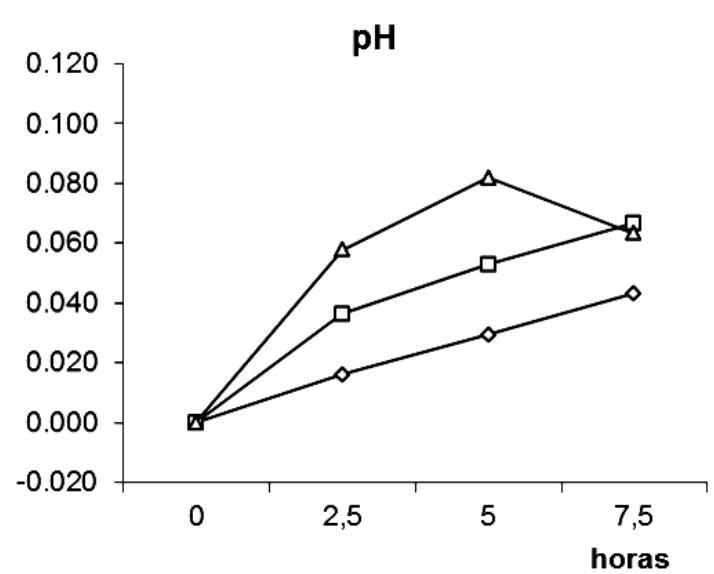

$\mathrm{HCO}_{3}^{-}$

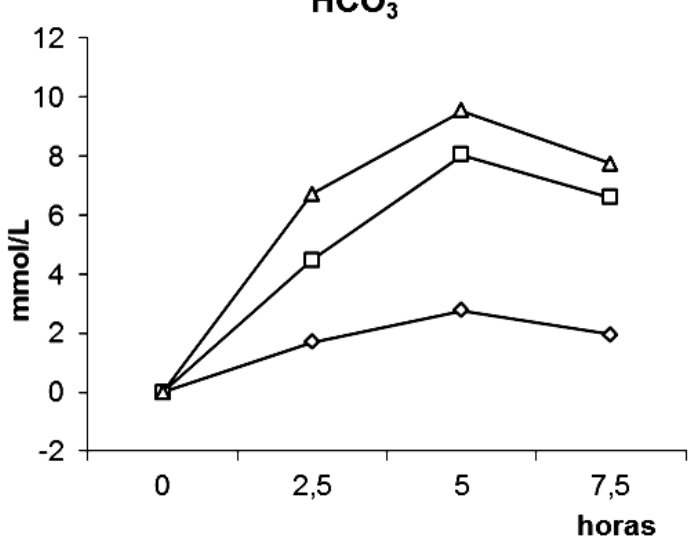

consideração a abordagem tradicional do equilíbrio ácido-base, centrada no bicarbonato, segundo a qual a metabolização de maior quantidade do lactato disponível aumentaria, direta ou indiretamente, o número de moléculas de $\mathrm{HCO}_{3}^{-}$(Kasari, 1999). A segunda considera a abordagem não tradicional, baseada no efeito dos íons fortes, os quais permanecem dissociados no plasma (De Morais e Constable, 2006). Essa abordagem define que a administração de soluções com SID efetiva elevada provocaria aumento da SID no plasma, com consequente efeito alcalogênico. A SID, calculada por meio da equação $\mathrm{SID}=\left(\mathrm{Na}^{+}+\mathrm{K}^{+}\right)-\mathrm{Cl}^{-}$, representa a relação entre os eletrólitos plasmáticos. O termo SID efetiva é empregado para a mesma relação nas soluções eletrolíticas, parenterais ou orais, administradas com fins terapêuticos (Constable, 2003).
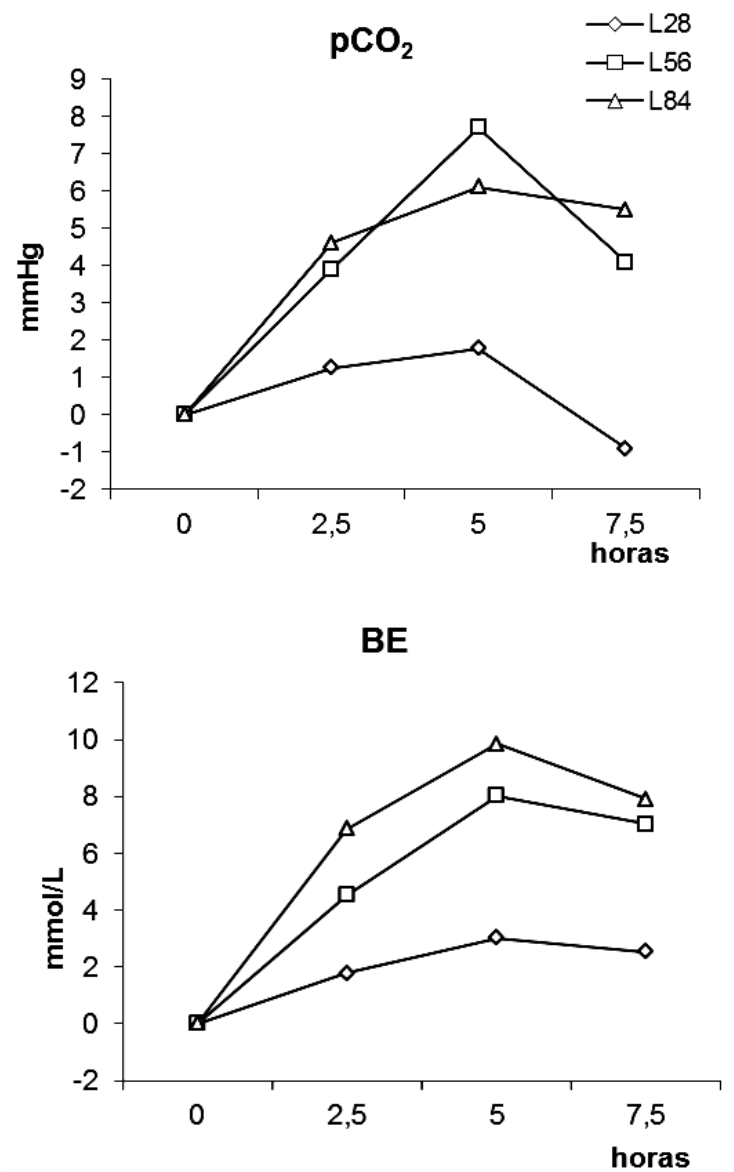

Figura 1. Valores médios da variação do $\mathrm{pH}$, da pressão parcial de dióxido de carbono $\left(\mathrm{pCO}_{2}\right)$, do bicarbonato $\left(\mathrm{HCO}_{3}{ }^{-}\right)$e do excesso de bases (BE) no sangue de bezerros sadios antes do início (0 hora), na metade (2,5 horas), ao término (5 horas) e 2,5 horas após o término (7,5 horas) da infusão de soluções eletrolíticas contendo 28,56 ou $84 \mathrm{mEq} / \mathrm{L}$ de lactato (L28, L56, L84). 
Quanto ao equilíbrio eletrolítico (Fig. 2), as concentrações plasmáticas de $\mathrm{Na}^{+}$se elevaram com a administração da L56 $(\mathrm{P}<0,01)$ e apresentaram tendência à elevação com a L84 $(\mathrm{p}=0,08)$. As duas soluções provocaram redução da concentração de $\mathrm{K}^{+}(\mathrm{P}<0,01)$ e tendência à diminuição do $\mathrm{Cl}^{-}(\mathrm{p}=0,08)$. Tomando-se como base os intervalos fisiológicos apresentados para bezerros (Benesi et al., 2005; Freitas, 2009), as observações ao término da infusão da L84 caracterizaram-se por hipernatremia leve $(144,0 \pm 5,25 \mathrm{mmol} / \mathrm{L})$, hipopotassemia leve $(3,49 \pm 0,23 \mathrm{mmol} / \mathrm{L})$ e normocloremia $(100,5 \pm 4,08 \mathrm{mmol} / \mathrm{L})$. As variações do $\mathrm{Na}^{+}$e do $\mathrm{Cl}^{-}$devem ter ocorrido como consequência direta da composição eletrolítica das soluções infundidas. A variação do $\mathrm{K}^{+}$, contudo, pode ser secundária ao desequilíbrio ácido-base iatrogênico. Nos estados de alcalose metabólica, a hipopotassemia pode ocorrer como resultado do ingresso do $\mathrm{K}^{+}$para o meio intracelular concomitante à saída de $\mathrm{H}^{+}$ para o extracelular (DiBartola, 2006).
Mais do que a concentração plasmática de cada um dos eletrólitos interpretada individualmente, a variação da SID no plasma dos bezerros reflete com maior fidelidade o desequilíbrio eletrolítico que se instalou como efeito das soluções com concentração elevada de lactato. Diferentemente da L28, ambas provocaram aumento da SID (Fig. 2) e a magnitude foi maior com a L84 $(\mathrm{P}<0,01)$, que ultrapassou o valor de referência de $43 \mathrm{mmol} / \mathrm{L}$ admitido para bezerros (Constable et al., 2005). A SID efetiva das soluções estudadas corresponde à concentração do lactato, sendo, portanto, $56 \mathrm{mEq} / \mathrm{L}$ e $84 \mathrm{mEq} / \mathrm{L}$ nas soluções L56 e L84, respectivamente. A manipulação da composição das soluções não envolve somente a modificação da concentração do lactato, mas, sobretudo, a redução proporcional da concentração do $\mathrm{Cl}^{-}$(Tab. 1). Em suma, as soluções L56 e L84 possuem composição que se diferencia da composição do plasma com concentrações altas de lactato e baixas de $\mathrm{Cl}^{-}$, o que produz aumento da sua SID efetiva.

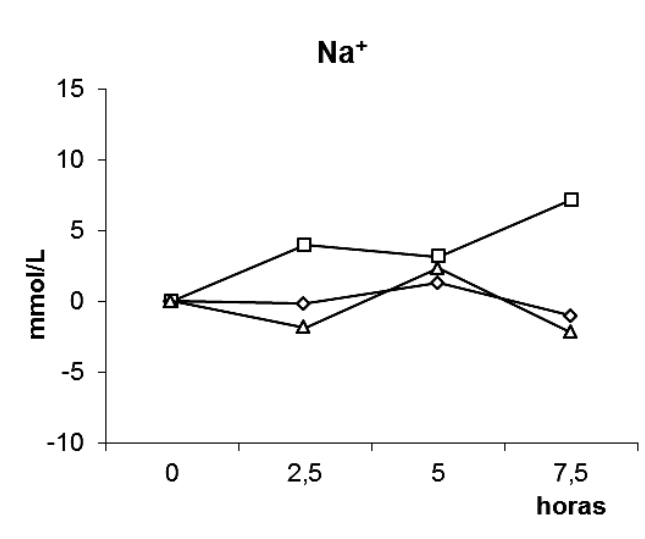

$\mathrm{Cl}^{-}$

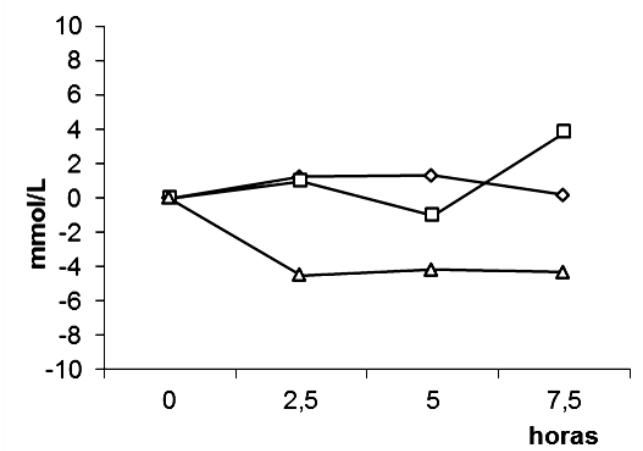

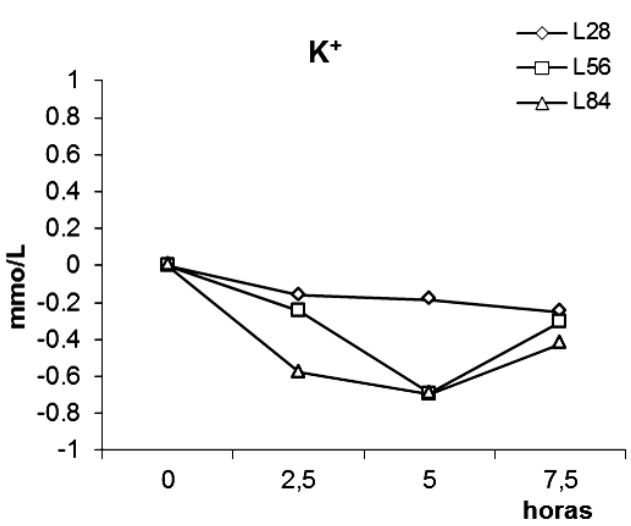

SID

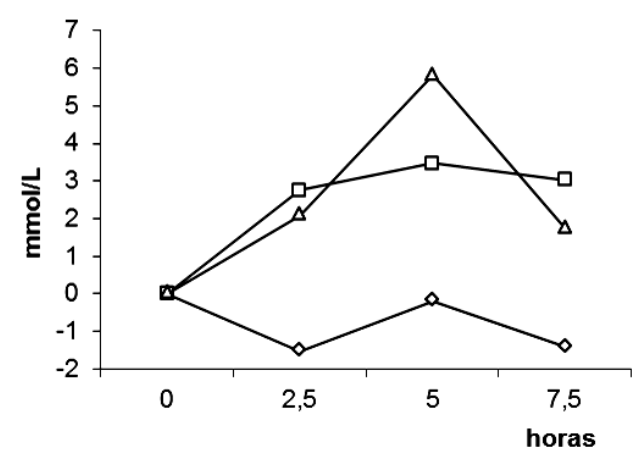

Figura 2. Valores médios da variação das concentrações de sódio $\left(\mathrm{Na}^{+}\right)$, potássio $\left(\mathrm{K}^{+}\right)$e cloro $\left(\mathrm{Cl}^{-}\right)$e da diferença de íons fortes (SID) no plasma de bezerros sadios antes do início (0 hora), na metade (2,5 horas), ao término ( 5 horas) e 2,5 horas após o término (7,5 horas) da infusão de soluções eletrolíticas contendo 28, 56 ou $84 \mathrm{mEq} / \mathrm{L}$ de lactato (L28, L56, L84). 
A infusão das soluções com SID efetiva maior do que a do plasma provocou elevação de $\mathrm{Na}^{+}$e diminuição de $\mathrm{Cl}^{-}$relativas, o que elevou a SID no plasma e produziu, consequentemente, o efeito alcalinizante observado (De Morais e Constable, 2006). Quanto maior a SID efetiva da solução, maior foi o impacto sobre a SID plasmática e, como consequência, mais acentuado foi o efeito alcalinizante produzido.

As soluções infundidas provocaram aumento das excreções fracionadas de $\mathrm{Na}^{+}(\mathrm{P}<0,01)$ e de $\mathrm{Cl}^{-}$ $(\mathrm{P}<0,01)$ (Fig. 3), mas não de $\mathrm{K}^{+}$, e isso ocorreu independentemente da composição da solução $(\mathrm{P}>0,05)$. O valor máximo foi observado ao final da infusão. Por se tratarem de bezerros hígidos, a eliminação urinária aumentada dos eletrólitos tornou-se necessária como mecanismo para manutenção da homeostase, evitando-se o desequilíbrio iatrogênico provocado pelos eletrólitos administrados em excesso. Duas horas e meia após o término da infusão, as excreções fracionadas já se aproximavam dos valores originais mensurados no início da infusão.

A hemodiluição iatrogênica caracterizou-se por reduções da PPT $(\mathrm{P}<0,001)$, do AG $(\mathrm{P}<0,001)$ e da $\mathrm{A}_{\text {tot }}(\mathrm{P}<0,001)$, efeitos produzidos por todas as soluções estudadas sem distinção entre elas $(\mathrm{P}>0,05)$. Comparados aos valores do início da infusão, os observados duas horas e meia após o final ainda estavam mais baixos, mas com tendência a retornarem à situação original. O excesso de fluido administrado nos bezerros não desidratados, com volume correspondendo a $10 \%$ do peso corporal, não provocou sobrecarga ou distúrbios circulatórios aparentes. Os bezerros mantiveram frequências cardíaca e respiratória inalteradas e não demonstraram alterações no padrão da respiração. $\mathrm{O}$ número de micções foi elevado durante e após a infusão, e a urina eliminada a partir da metade da infusão apresentava densidade baixa (médias entre 1005 e 1010) comparada à do início (médias entre 1024 e 1031) ( $\mathrm{P}<0,001)$. Assim como já mencionado para os eletrólitos, a excreção renal eficiente do excesso de fluido administrado exerceu papel fundamental para a manutenção do equilíbrio hídrico nos bezerros incluídos no estudo.

Além da manutenção da homeostase hídrica e eletrolítica, os rins contribuíram para amenizar o desequilíbrio ácido-base iatrogênico, passando a eliminar urina alcalina. $\mathrm{O} \mathrm{pH}$ urinário se elevou de $6,300 \pm 1,024,6,140 \pm 1,165$ e $6,516 \pm 1,305$ antes de os bezerros receberem as soluções, para $7,483 \pm 0,327,7,328 \pm 0,765$ e 7,998 $\pm 0,183$ ao final das infusões de L28, L56 e L84, respectivamente. A elevação foi contínua ao longo da infusão e proporcional ao efeito alcalinizante sistêmico que cada solução produziu $(\mathrm{P}<0,001)$. Duas horas e meia após o final da infusão, os bezerros que receberam L56 e L84 eliminavam urina ainda mais alcalina, com $\mathrm{pH} 7,710 \pm 0,688$ e 8,216 $\pm 0,179$, respectivamente. A alcalinização da urina se deve à maior eliminação de $\mathrm{HCO}_{3}{ }^{-}$, que passa a ser menos conservado pelos rins. Essa é a resposta fisiológica do organismo nos estados de alcalose metabólica, e ela se instala como um mecanismo necessário para a correção do desequilíbrio (DiBartola, 2006).

A concentração do lactato L no plasma mantevese inalterada nos bezerros que receberam L28 e L56 e se elevou discreta e unicamente na metade da infusão de L84 (Fig. 3), quando alcançou o maior valor médio $(2,898 \pm 1,405 \mathrm{mmol} / \mathrm{L})$. Não houve diferença entre as soluções que continham lactato $(\mathrm{P}>0,05)$, e as concentrações observadas não ultrapassaram o intervalo de referência apontado para bezerros (Freitas, 2009). A excreção fracionada do lactato L também não se alterou com as infusões das soluções (Fig. 3), e isso é a prova de que, mesmo no caso da solução com a maior concentração (L84), o lactato infundido foi efetivamente metabolizado pelo organismo e não eliminado por excreção urinária. A administração da L84 não provocou hiperlactatemia, provavelmente, porque a distribuição e a metabolização do lactato ocorrem rapidamente. $\mathrm{O}$ efeito alcalinizante foi, portanto, imediato e alcançou a magnitude máxima ao término da infusão (Fig. 1).

As soluções contendo bicarbonato de sódio (B28, B56 e B84) foram empregadas neste estudo e serviram como padrão de referência para a comparação com as soluções equivalentes contendo lactato de sódio (L28, L56 e L84), uma vez que o $\mathrm{HCO}_{3}{ }^{-}$exerce efeito tampão imediato porque, ao contrário das bases metabolizáveis, não necessita sofrer metabolização (Kasari, 1999; Constable, 2003). Não se observaram diferenças entre as soluções equivalentes para a maioria das variáveis estudadas $(\mathrm{P}>0,05)$, ou seja, as soluções com lactato produziram efeitos 
similares aos das soluções com concentrações equivalentes de bicarbonato. Esses resultados são, de forma geral, compatíveis com os obtidos por Flaiban et al. (2009) em ovelhas sadias infundidas com as mesmas soluções e comprovam que a metabolização do lactato é rápida nos ruminantes, independentemente da idade, e o suficiente para produzir alcalinização equivalente à do bicarbonato.
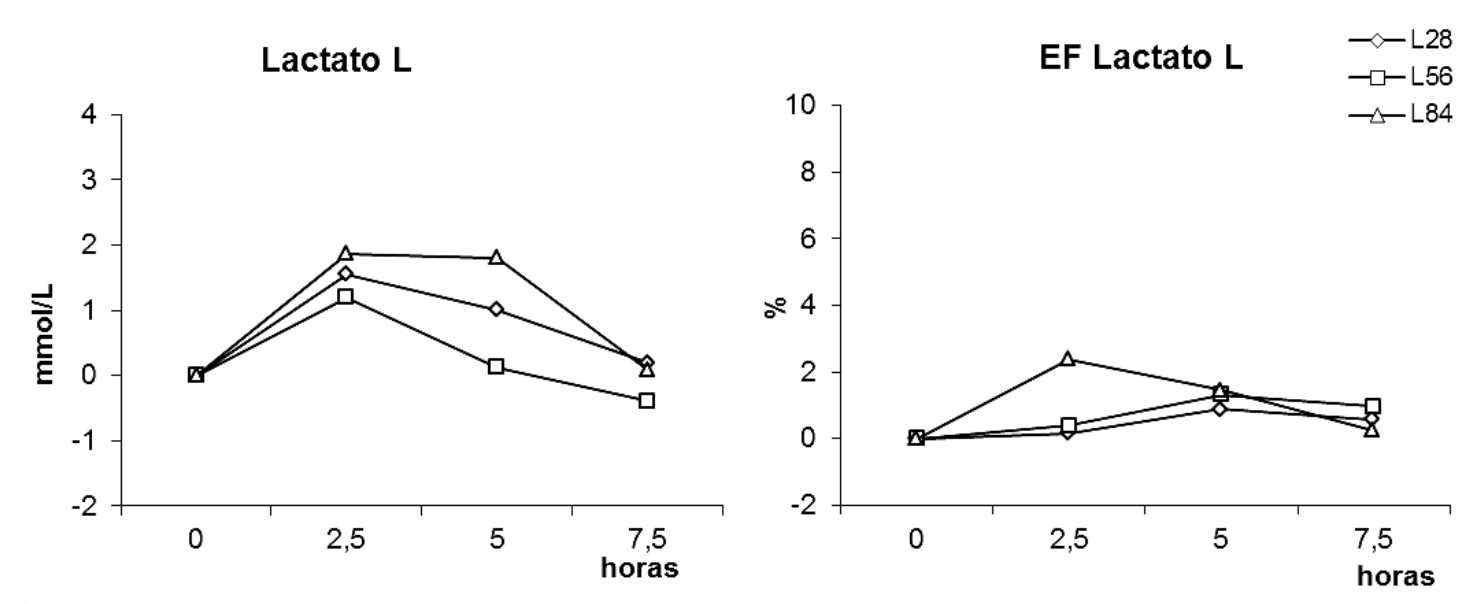

$\mathrm{EF} \mathrm{Na}{ }^{+}$
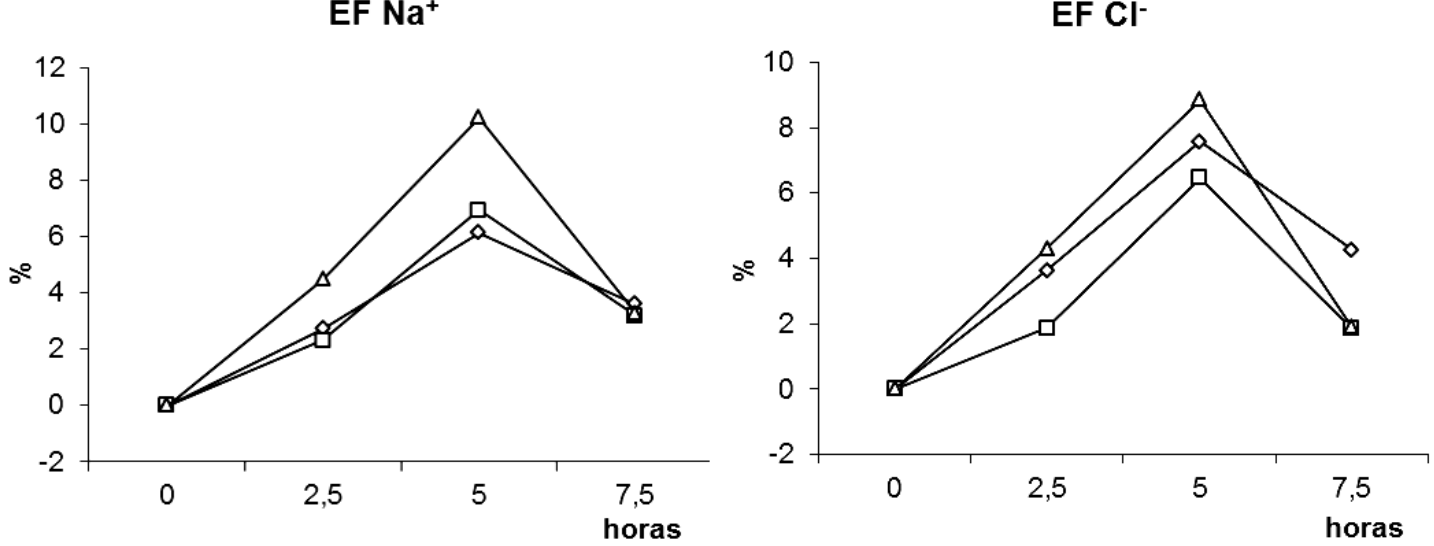

Figura 3. Valores médios da variação da concentração plasmática de lactato L e das excreções fracionadas (EF) urinárias de lactato L, de sódio e de cloro de bezerros sadios antes do início (0 hora), na metade (2,5 horas), ao término (5 horas) e 2,5 horas após o término (7,5 horas) da infusão de soluções eletrolíticas contendo 28, 56 ou 84mEq/L de lactato (L28, L56, L84).

Evidências anteriores em tanto em bezerros sadios (Naylor e Forsyth, 1986) quanto em garrotes sadios (Leal et al., 2007) já indicavam efeitos alcalinizantes similares entre o bicarbonato e o lactato L em solução. Nesses estudos, contudo, foram empregadas soluções contendo $150 \mathrm{mEq} / \mathrm{L}$ de lactato (quase o dobro ou o triplo das concentrações utilizadas no presente trabalho) e sem outros eletrólitos associados na sua composição. As soluções estudadas apresentam como vantagem o fato de veicularem maior número de eletrólitos e permitirem a reposição deles. Embora a L56 e a L84 não possam ser consideradas soluções eletrolíticas balanceadas como a SRL, porque possuem composição diferente da composição do plasma, elas não causaram efeitos colaterais, comprovando-se seguras. Apresentam indicação terapêutica nos casos em que a acidose metabólica venha acompanhada por desidratação e desequilíbrios eletrolíticos. A solução L84, administrada em volume correspondente a $10 \%$ do peso corporal, foi capaz de produzir incremento médio de $10 \mathrm{mmol} / \mathrm{L}$ no $\mathrm{BE}$ de bezerros sadios. Na prática, quando administrada em animais enfermos em volume igual ao 
utilizado no presente estudo, essa solução seria capaz de corrigir os graus moderados de desidratação (10\% do peso corporal) e de acidose metabólica $(\mathrm{BE}=-10 \mathrm{mmol} / \mathrm{L}$; Koch e Kaske, 2008), além de promover a reposição do sódio e do potássio, apresentando-se como opção eficaz para o tratamento de bezerros diarreicos. Essa hipótese precisa ser testada em estudo posterior.

\section{CONCLUSÃO}

Pode-se concluir que a solução eletrolítica com concentração elevada de lactato de sódio $(84 \mathrm{mEq} / \mathrm{L})$ produz efeito alcalinizante suficiente para a correção do grau moderado de acidose metabólica quando infundida em volume correspondente a $10 \%$ do peso corporal e não provoca efeitos colaterais em bezerros sadios. A sua eficácia terapêutica deve ser comprovada em estudos futuros com bezerros desidratados e acidóticos.

\section{AGRADECIMENTOS}

À médica veterinária residente Mariana Cosenza e aos acadêmicos de medicina veterinária da UEL Maria Luísa de Lima Landman, Leandro Silva Zechetto, Evandro Doine Vettorato, Juliana Maria Lopes e Fernanda de Castro Stievani, pelo auxílio durante a execução do experimento.

\section{REFERÊNCIAS}

BENESI, F.J.; COELHO, C.S.; LEAL, M.L.R. et al. Parâmetros bioquímicos para avaliação da função renal e do equilíbrio hidroeletrolítico em bezerras sadias, da raça Holandesa, no primeiro mês de vida. Braz. J. Vet. Res. Anim. Sci., v.42, p.291-298, 2005.

CONSTABLE, P.D. Fluid and electrolyte therapy in ruminants. Vet. Clin. Food Anim., v.19, p.557-597, 2003.

CONSTABLE, P.D.; STÄMPFLI, H.R.; NAVETAT, H. et al. Use of a quantitative strong ion approach to determine the mechanism for acid-base abnormalities in sick calves with or without diarrhea. J. Vet. Intern. Med., v.19, p.581-589, 2005.

CURI, P.R. (Ed). Metodologia e análise da pesquisa em ciências biológicas. 2.ed. Botucatu: Gráfica e Editora Tipomic, 1998. 263p.
DE MORAIS, H.A.; CONSTABLE, P.D. Strong ion approach to acid-base disorders. In: DiBARTOLA, S.P. (Ed). Fluid, electrolyte, and acid-base disorders in small animal practice. 3.ed. St Louis: Saunders Elsevier, 2006. p.310321.

DiBARTOLA, S.P. Metabolic acid-base disorders. In:__. (Ed). Fluid, electrolyte, and acid-base disorders in small animal practice. 3.ed. St Louis: Saunders Elsevier, 2006. p.251283.

FLAIBAN, K.K.M.C.; ROMÃO, F.T.N.M.A.; SILVA, R.S. et al. Potencial alcalinizante de soluções intravenosas de lactato e de bicarbonato de sódio administradas em ovelhas sadias. Cienc. Anim. Bras., v.10, p.176-180, 2009.

FREITAS, M.D. Avaliação dos parâmetros clínicos e laboratoriais de bezerras com diarreia neonatal naturalmente adquirida. 2009. 79f. Dissertação (Mestrado em Ciência Animal) Escola de Veterinária, Universidade Federal de Minas Gerais, Belo Horizonte.

GARRY, F.; CHEW, D.J.; RINGS, D.M. et al. Renal excretion of creatinine, electrolytes, protein, and enzymes in healthy sheep. Am. J. Vet. Res., v.51, p.414-419, 1990.

HARTSFIELD, S.M.; THURMON, J.; BENSON, G. Sodium bicarbonate and bicarbonate precursors for treatment of metabolic acidosis. J. Am. Vet. Med. Assoc., v.179, p.914-916, 1981.

KASARI, T.R. Metabolic acidosis in calves. Vet. Clin. Food Anim., v.15, p.473-486, 1999.

KOCH, A.; KASKE, M. Clinical efficacy of intravenous hypertonic saline solution or hypertonic bicarbonate solution in the treatment of inappetent calves with neonatal diarrhea. $J$. Vet. Intern. Med., v.22, p.202-211, 2008.

LEAL, M.L.R.; MORI, C.S.; ORTOLANI, E.L. Estudo da capacidade alcalinizante de tampões metabolizáveis em bovinos sadios. Arq. Bras. Med. Vet. Zootec., v.59, p.965-970, 2007.

LISBÔA, J.A.N.; BENESI, F.J.; MARUTA, C.A. et al. Tempo de viabilidade de amostras de sangue venoso bovino destinadas ao exame hemogasométrico, quando mantidas sob conservação em água gelada. Cienc. Rural, v.31, p.271-276, 2001. 


\section{Junqueira et al.}

LISBÔA, J.A.N.; BENESI, F.J. LEAL, M.L.R. et al. Efeito do tempo após a ingestão de leite sobre o equilíbrio acido-básico de bezerros. Arq. Bras. Med. Vet. Zootec., v.55, p.763-765, 2003.

LISBÔA, J.A.N.; FLAIBAN, K.K.M.C.; LANDMAN, M.L.L. et al. Potencial alcalinizante da solução de Ringer com lactato em bezerros sadios. Arch. Vet. Sci., v.12, p.90-91, 2007.
NAKAGAWA, M.; SUZUKI, K.; TAKAHASHI, F. et al. Comparison of the alkalizing effects of bicarbonate precursors in calves with experimentally induced metabolic acidosis. $J$. Vet. Med. Sci., v.71, p.807-809, 2009.

NAYLOR, J.M.; FORSYTH, G.M. The alkalinizing effects os metabolizable bases in the healthy calf. Can. J. Vet. Res., v.50, p.509-516, 1986. 